they are fully produced, and their connexion with the original ophthalmia may then easily be lost sight of. They are almost irremediable, because nothing can restore the natural sbape, texture, and pliability of the lids, and because operations for altering the position of the eyelashes are often defeated by the continuance of the contraction, which, in a few months, may reproduce the deformity. The patients are, perhaps, more forlorn and to be pitied than any other class that fall under our notice. They are in a state of constant pain or uneasiness, tormented by every movement of their eyelids, tormented by every particle of dust which falls into their eyes, tormented by their eyelashes, tormented by constant overflow of tears, seldom with sufficient vision to follow any employment, dependent upon the rates or on charity, balf blind, and wholly miserable. Such are the ultimate results produced by contagious ophthalmia, when the patienta pass away from nuder treatment before they are completely cured. If the little girl whom you have seen were now to make her escape from the doctor such would be the condition to which she would come in the course of years. I repeat, therefore, that if the immediate destruction of eyes by acute ophthalmia were unknown, the prevalence of the disease would still be a matter of the highest importance alike to the sufferers and to the public. We have no data that I am aware of for estimating the degree of prevalence with any sort of accuracy. But I have been told the cases at Hanwell alone amounted to some hundreds; that the cases at Anerley were somewhere about two hundred; and I have no doubt that a complete enumeration of the sufferers, during the last ten years, at the various workhouses and schools in the kingdom, would take us far into thousands of cases.

My third and, perhaps, most important proposition is that contagious ophthalmia is not an affection which can be introduced into and propagated among a community of healthy persons. If you take a drop of matter from an eye in the acute stage and put it into a healthy eye, or if you expose the healthy eyes of a vurse to the manifold chances of direct contact and to the concentrated atmospheric contagion of a ward containing a number of infected children, some kind of inflammation will no doubt be produced. But before it can spread in the ordinary manner, contagious ophthalmia must find persons prepared for its reception by the existence of an antecedent morlid condition. This antecedent condition is not one of mere ill-health or debility, either inherited or acquired, but it is something definite, manifested by the development, in the lining membrane of the eyelids, of certain little bodies which are not unlike grains of boiled sago, and which are commonly called after this resemblance. In technical nomenclature they are known as "follicular granulations," but to-day I will call them "sago grains." They are concealed by the eyelids when these are in their natural position, and when once ophthalmia is set up, they are soon concealed altogether by the swelling and the increased redness of the parts in which they are found. Here again, example being better than description, I have a patient in attendance who has the "sago grains," but who has not yet suffered from ophthalmia. The very existence of these "sago grains" remained unknown until the year 1848, when they were discovered by $\mathrm{Dr}$. Löfler, the surgeon to a Prussian regiment employed against the Danes. Soldiers on active service have often suffered greatly from contagious ophthalmia, and it prevailed so much in the regiment in question that many men were disabled. Dr. Löffer, in order to treat every case at the very beginning, caused the whole regiment to be paraded daily for inspection, and he examined the inside of the eyelids of every man. In a large proportion of the apparently unaffected men he found these "sago grains," and at first he did not know what they were or what they signified; but after a while he found that the men who had sago grains were sooner or later attacked by ophthalmia, and that the men who had no sago grains remained exempt. The inquiry was next taken up, and diligently pursued, in the British army, chiefly by Drs. Frank, Marston, and Welch. They confirmed the conclusions at which Dr. Löfller had arrived, and they established that the prevalence of the sago grains is the necessary antecedent of an epidemic of contagious ophthalmia. They furnisb, to repeat a figurative expression I have already used, the soil in which the seeds of the disease germinate; and, if the soil is wanting, the seeds either remain quiescent or, at most, produce disease of a comparatively harmless character. Drs. Frank, Marston, and Welch further established that, when a large number of persons are brought together in close aggregation, and are exposed to insanitary conditions of living, they become the subjects of these sago grains, so that the presence or absence of sago grains affords a delicate test of the sanitary state of a school, regiment, or any similar community. In a regiment the proneness to the development of sago grains is found to decrease as life advances-that is, to be much greater in young soldiers than in old ones, and, by a parity of reasoning, it is assumed to be greater in a community of children than in a community of adults. In any individual, and therefore in any community, the sago grains may disappear without producing mischief. But, as a matter of fact, sources of irritation to the eyes abound in the world, and when these sources of irritation act upon eyelids in which sago grains are already present they often excite the contagious form of ophthalmia. It is, therefore, very rare for a community in which sago grains are prevalent to remain for any length of time free from an outbreak. The next step in the inquiry was to determine the nature of the sago grains; and this has been accomplished only within the last two years. Speaking broadly, they may be regarded as enlarged glands, and as bearing considerable analogy to the enlarged glands sometimes seen in feeble or scrofulous children. You know that glands are natural structures, which, in their healthy state, are not discoverable externally either by sight or touch, but which, in certain unhealthy conditions, become manifest as hard prominences on the sides of the neck and in other situations. When thus manifest, they may eitber remain passive, or, as it is said, indolent, and may after a time disappear by returning to their natural state, or they may undergo an unhealthy form of inflammation and become the seat of abscesses, which often give rise to unsightly scars. The case of the sago grains is almost precisely parallel, for just as a child will not have scrofulous abscesses in its neck unless glandular enlargement has first. existed, so a child will not have contagious ophthalmia unless sago grains have first been developed in its eyelids. In this fact, therefore, we possess a clue to the prevention of the disease.

(To be concluded.)

\section{HYSTERIA SIMPLIFIED AND EXPLAINED.}

\section{Bx D. Dm BERDT HOVELL, F.R.C.S.E.}

THere is still so much absence of sound knowledge of the disease called hysteria, and so much mystery attached to it, that it seems excusable, if not desirable, to attempt to elucidate it.

The meeting of the Clinical Society on October 31st may be taken as a fair representation of the present state of opinion and general information on the subject. Sir W. Gull called attention to a disease which he had formerly termed " apepsia hysterica," but which he now preferred to call " anorexia hysterica," occurring mostly in young women between the ages of fifteen and twenty-three. I submit that the term "puellaris" would more correctly designate the disease, as regards the age at which it most frequently occurs, and the usual suhjects of it. If medicine be not one of the exact sciences, there is no reason why we should not be correct and definite in our terms. At the outset I am at issue with Sir W. Gull, when he says that "we may call the state 'hysterical' without committing ourselves to the strict etymological value of the word," for this simple reason, that it is the false derivation of the word which not only involves the disease in obscurity, but misleads as to its actual condition.

I venture to take further exception to Sir W. Gull's description, when he says that "the want of appetite is due to a morbid mental state," and "it is notorious that certain mental states are apt to destroy the appetite," and "it would be admitted that young women of the age named are especially obnoxious to mental perversity."

Although the mental and moral conditions of our nature are closely associated psychologically, they are quite distinct: 
the one represents the intellect, the other the feelings or emotions. I therefore venture to assert that when Sir $W$. Gull uses the term " mental," he really means moral. It is true that mental excitement, if there be such a thing pare and simple, will take away appetite, but it would be more correct to say that loss of appetite is frequently associated with morbid psychological states. The two do not stand to one anotber in the relation of cause and effect. Again, I should restrict the term "mental perversity" to either the vagary of an imperfect intellect or the moral obliquity which prevents a capable mind from seeing or admitting an obvious truth. To insist upon these definitions is not a mere whim; in order to understand the matter it is imperative that we should distinguish, and accurately bear in mind, the physical, mental, and moral; because if we do not clearly comprehend them separately, it is impossible to form an accurate opinion of their conjoint relations.

The following case illustrates the misuse of the term hysteria. A few months ago I met one of the physicians attached to a large metropolitan hospital who told me that in such a ward I should find a case of hysteria which would interest me. I went up accordingly, and found a woman ill in bed, agitated and nervous, with imperfect speech, want of power and control in her limbs, inability to stand or walk, \&c.; and learned that her illness had been caused by a severe moral shock-viz., finding her husband in bed with another woman. I say moral in direct contradistinction to hysterical, because I maintain that the shock fell upon the nervous system, and not upon the uterus. A few weeks after I observed in the medical journals that this physician had exhibited at the Pathological Society a specimen representing the following train of symptoms: "Weakened intellect, with staccato speech, jerking, palsy, and involuntary action of limbs, head, and trunk; retained sensibility of skin and muscles, freedom from pains of locomotor ataxy." had no difficulty in recognising the accurate detail of the case of "hysteria" (?).

Either this unfortunate patient was in sound health at the time of the occurrence or disease was already incipient. In the first case it is clear that the shock was the cause of the disease; in the second the proximate cause of its development. That such are the direct effects of shock is the first point on which $I$ insist; also that in all these cases we have to deal with reduced power in some form or other. But if we should unreasonably determine to designate either of these conditions hysteria, what possible pretext or excuse can there be for examining the patient with the speculum which has been gravely advocated in all cases of hysteria? What are we to understand by hysteria? In the instance above it is either a disease caused by shock or accelerated thereby. To my mind, the morbid condition thus caused or induced would be better designated by the term neurosis, which more reasonably implies, if it does not more accurately define, it.

Neurosis is the effect of physical as well as moral shock (of this I have given instances elsewhere*). The symptoms of both are identical in many respects. It is also frequently induced by depressing and exhausting physical disease. The main conditions are-loss of physical power, loss of moral power, increased susceptibility to pain and to all sources of irritation, and certain phases of disease. To repeat, the morbid condition so long miscalled hysteria is essentially connected with a depressed or rather low condi. tion of nerve power. In the generality of instances it is caused by some blow or shock, physical or moral, or by some depressing moral circumstances; it is also frequently induced, as well as protracted, by some depressing or exhausting physical cause. These two, the moral and the physical, act and react upon one another. The disease often exists in a passive state, which also is very obnoxious to all causes and sources of irritation, by which it is often unexpectedly, and at times unaccountably, developed into an active stage. Those most liable to it are obviously the feeble and sensitive, in contradistinction to the strong and unfeeling. The symptoms of the disease are often complicated as well as protean, and under the best treatment the cases are at times both tedious and troublesome, because the original circumstances are but slowly recovered from. One reason of this is that the power of recovery is not great. Generally speaking, the so-called hysterical state is simply one of emotional

* Inquiry into the Real. Nature of Hysteria. susceptibility. The object of treatment is to raise power and remove sources of irritation; but it is useless to at tempt the former until the latter has been attended to, and herein lies the difficulty of the matter. It is ever to be borne in mind that the disease is moral as well as physical and so must also be the treatment; and if it be important to remove physical sources of irritation and to raise physical power, a fortiori is it imperative to improve moral power which we shall in vain attempt to do till we have removed moral sources of irritation. This is, as it were, the crucial point-if one may make use of so absurd a mathematical term - in the treatment of the disease which $I$ have so long insisted on and in vain striven to get recognised. Here it seems to me that the physician-aye, and surgeon too-have frequently become the subjects of the " morbus hystericus," inasmuch as they have become the subjects of "mental perversity," and are not wholly free from a certain amount of "moral obliquity"; for here, instead of being therapeutic and curative, the doctor has become vindictive, and desired to punish the patient whom his own want of skill has failed to relieve. And when the poor patient has, for nobody knows how long, "suffered many things of many physicians, and been nothing bettered, but rather grown worse," then, forsooth, comes a genius who talks about "a craving for sympathy"; and well might the patient have the craving for what most assuredly she has never met with. Craving for sympathy would, perhaps, be better interpreted the craving created by long want of help. Powerlessness and a sense of helplessness naturally lead such patients to seek for aid. One main difference between the hypothesis of hysteria and that of neurosis is that the first is apt to regard complaints as unreal and fictitious, the result of wilfulness and obstinacy and the aforesaid moral obliquity in various forms; while the second deals with facts instead of imputing motives. The hysterical doctrine is positively mischievous; it first misleads because it does not comprehend, and it cannot possibly treat with judgment a disease which it considers to be unreal. Thus, instead of elucidating, it only envelopes in a cloud, or rather fog, and does harm rather than good. On the other hand, we have only to recognise the state of neurosis and its tendencies as the effect of shock, \&c., and examine the various symptoms in detail, to make the treatment of these cases not only not vexatious, but positively interesting; at least, so it has proved to me. In a word, treat the patients firmly if you will, but kindly and reasonably; meet disappointment with cheerfulness, irresolution with encouragement; if they are perverse and wilful, do not irritate, but improve their moral tone. Still less should we be harsh and vindictive; our province is to heal, and not to judge.

Much of the evil that has arisen from the term hysteria is due to that lamentable paper of the late Dr. Addison on "Uterine Irritation." By means of that paper-one of the most illogical essays that ever was written-he not only extensively propagated, but lent the weight of his authority to the pernicious doctrines which have so unfortunately attached themselves to it. The beauty of it is that the symptoms there detailed under the head of " uterine irritation" do not lead to the state usually designated by the obnoxious name. Nymphomania is one thing, but the state called hysteria is owing to another set of causes altogether. In a word, the one is moral as regards its psychological character, the other wholly immoral; but in the morbus hystericus the moral and immoral have been jumbled up in the medical mind in a most distressingly unaccountable manner.

Having divested "anorexia puellaris" of its mystifying designation, the disease admits of a simple explanation. It appears to occur in patients whose physical or moral power, or both, are depressed, although the intëllect is not necessarily disordered. In such patients some source of irritation is acting -it may be disordered stomach or loaded rectum; and it does appear that in some cases the disease exists in an extreme degree. The indications of treatment seem to be obvious: to administer suitable medicines and to unload the rectum; meanwhile, as Dr. Quain suggested, to administer nourishment and stimulants in frequent and suitable quantities by mouth and per rectum. The administration of nourishment must necessarily be imperative, even though it should not be retained. So far: we are taking means to remove sources of irritation and to raise 
playsical power. I have only to add, that if the neurosis, which seems to be an essential condition of the disease, possibly induced by loss of strength cousequent on insufficient nourishment, - if the neurosis be moral as well as physical, then, as a matter of course, similar moral treatment must be instituted as indispensable to recovery. If the patient be an ignorant peasant girl, whose tendency to " moral obliquity" has been fostered by her parents for the sake of gain, we should at once settle the question of her not taking food by insisting that nourishment is given in some form or other, and having settled the physical question, then proceed to improve the morale; but we ought not to indulge our own "mental perversity" by insisting upon starving the poor thing to death in order to satisfy the credulous portion of the community that she cannot live upon air.

The loss of moral control, or, in point of fact, temper, is so obvious a consequence of loss of moral power, that if it had not been so frequently overlooked it would hardly call forth notice. It is, however, not only a common but an important point to be borne in mind. Captain - - had the convoy of seven vessels from Spain to this country at the latter end of the year 1872. In consequence of bad weather six were lost. He put into Falmouth having had an anxious and laborious week, during which he had taken little or no food, as he was suffering from cynanche tonsillaris. The medical practitioner there advised him to stay on shore, but, having taken on board a pilot and another captain, he continued the voyage. The ship was lost on the Goodwin. He was the last man to leave the vessel, for the loss of which he was tried and acquitted. The effect of the strain and anxiety was to cause great irritability and loss of control in form of loss of temper upon slight provocation. On the 23rid of October, 1873, he had an altercation with the owner of the ship in which he was about to go to sea, in consequence of which he lost his command, and was summarily dismissed with violence. I found him late in the evening asleep, but the practitioner by whom he was first seen thought he was drunk, for which charge there was not the slightest foundation. His condition generally was prostration of nerve power or neurosis. He soon recovered his usual state of bealth.

Some years ago a case of what had been previously termed hysterical joint came under my care. A pale, delicate girl fell in the drawing.room and hurt her knee. She declared that for seven years she was never free from pain; and here let me remark that the complaints of such patients are of ten better founded than they appear to be, and require careful investigation before they are pronounced fictitious,

for "They speak truth who breathe their words in pain."

In this patient there was nothing that the most superficial could reasonably have termed "hysterical." Her account of herself was plain and direct. Various remedies did little, however, to improve her condition. She persistently complained of pain after walking a short distance. A splint, which effectually preserved the joint from motion, enabled her to walk a longer distance; but in all other respects her want of progress was a source of dissatisfaction to me and regret to her friends. One day her mother asked me if there was any danger, to which I replied, No; but in the night a violent thunderstorm came on, of which she had a great dread. She got out of bed and walked to the nightchair, when, in addition to a severe attack of diarrhœa, she had vomiting; and there she died-illustrating a feeble state of nerve power at any rate. On examination the cartilage of the tibia was partially absorbed.

The term "hysterical joint" is quite as open to criticism as any other application of this really absurd and objectionable nomenclature. Without doubt Sir Benjamin Brodie did essential service in his day by pointing out the difference between organic disease and the nervous affection of a joint. But that is more than a quarter of a century ago; and it is high time to make some advance upon that position. With due deference to Sir James Paget, the term "neuromimesis" does not much help the matter. The point is still one of diagnosis. The question still lies between the existence of organic disease and a nervous affection. The fact that the one simulates and masks the other maintains the necessity for the distinction to be drawn clearly between the two. It does not in any way divest the subject of its mischievous tendencies, or lead to any improvement in treating the disease. On the other hand, if the state of neurosis be admitted, its actual condition, its liabilities and susceptibilities at once call for investigation and explanation. If we once realise the fact that the state is essentially one of loss of power, that it is obnoxious to pain, to irritation, to spasm, both tonic and clonic; if we determine that this state is not merely physical, but requires also a distinct psychological recognition,- -then we not only open a field of observation which explains all the phenomena, but at the same time find indications of ratiunal treatment we at once improve, not only our diagnosis, but our thera peutics also. In point of fact, we open up another phase of "the constitutional treatment of local disease" on which the late Mr. John Scott used so much to insist. No apology is made for the direct imputation that, in the estimation of these affections, the doctor has been at times the subject of the "morbus hystericus" as well as, or perhaps even more than, the patient. An obstinate case of hysteria is a case of mismanagement; and this mismanagement has, in not a few instances, gone on to the "bitter end" of the death of the patient. There is no better attribute of the medical mind than that it seeks truth, to divest itself of prejudice, to correct error; and in no instance are these attributes and qualifications capable of being exercised to greater advantage than in this much misunderstood and badly treated disease. Five Houses, Clapton.

\section{ESMARCH'S BANDAGES FOR BLOODLESS} OPERATIONS.

\section{A CLINICAL NOTE。}

BY SAMPSON GAMGEE, F.R.S.E., SURGXON TO THR QUREN's HOSPITAX, BIRMINGHAK.

IMPREssed by the results recorded by Professor Humphry of Cambridge, I resolved (29th Nov. ult.) to test the value of Esmarch's bandages for bloodless operations. The patient, a youth aged nineteen, was suffering from acute caries of the middle third of the left femur. Chloroform having been administered and the heel well raised, I bandaged tightly, with india-rubber bandages two inches wide, from the roots of the toes, over the heel, to a point two inches above the intended seat of operation. While an assistant held his finger on the uppermost turn of bandage, the limb immediately above it was very firmly encircled with several turns of india-rubber pipe, about the thickness of the index-finger. The ends of the pipe, which was two yards long, having been firmly tied together, the elastic bandage was uncoiled, leaving the limb shrunken and waxy pale. A three-inch incision in the middle line down to the femur, free use of the gouge and chisel in the removal of a quantity of carious bone, an incision into a boggy spot inside the $\mathrm{knee}$, and the passage of a drainage-tube through the opening thus made from the incision over the middle third of the bone, were the successive steps of the absolutely bloodless operation. The scanty, pale, serous exudation was barely sufficient to impart a light-yellow stain to a white handkerchief. The elastic cord once freed and allowed to uncoil, pink suffusion of the previnusly dead-looking limb was the work of a few seconds. Blood now trickled from the wound, but certainly not more freely than usual after such an operation. Subsequent progress has been most satisfactory. The lad is easy and feeding, the femur is re duced to nearly normal size, the discharge lessening, and the wound rapidly granulating.

In addressing the clinical class immediately after the operation, it was impossible to conceal the enthusiastic admiration of the proceeding counselled by the German professor. Only the other day one of our leading surgeons spoke as if operative surgery had reached the utmost bounds of perfection. Esmarch's perfectly simple and efficient contrivance, which any surgeon can employ with success, renders possible the utmost economy of the vital powers, and scientific precision in the performance of many surgical operations. As the lad lay on the table in deep sleep, with the long drainage-tube stretching between the pale and spotless wounds through the substance of the thigh, it was impossible to suppress grateful admiration for the triple triumph of international surgery. This country 